\title{
Control of Electrical Resistance and Temperature of Titanium Dioxide Film by Local Heating with CW Fiber Laser
}

\author{
Togo Shinonaga*, Masahiro Tsukamoto**, Masanari Takahashi*** and Nobuyuki Abe** \\ * Graduate School of Engineering, Osaka University, 1-1 Yamadaoka, Suita, \\ Osaka 565-0871, Japan \\ E-mail: togo@jwri.osaka-u.ac.jp \\ ** Joining and Welding Research Institute, Osaka University, 11-1, Mihogaoka, Ibaraki, \\ Osaka, 567-0047, Japan \\ **** Osaka Municipal Technical Research Institute, 1-6-50 Morinomiya, Joto-ku, \\ Osaka, 536-8553, Japan
}

\begin{abstract}
Titanium dioxide $\left(\mathrm{TiO}_{2}\right)$ film has photocatalytic properties and good biocompatibility. To expand the film application, formation of oxygen deficiencies in the film was one of the useful methods. Electrical resistance of the film can be decreased due to oxygen deficiencies formation. The local heating process in vacuum is a useful method to create the oxygen deficiencies in local area of the film. Electrical resistance might be locally decreased by local heating with a CW fiber laser. In our experiment, the films were irradiated with the laser in vacuum. Control of temperature on the film was very important for reducing the electrical resistance. Therefore, temperature monitoring of the laser focusing spot area on the film was performed. Temperature of the laser focusing spot area was increased as the laser intensity was increased. Then, the electrical resistance of the laser focusing spot area was decreased as the laser intensity was increased. Thus, electrical resistance of the laser focusing spot area was decreased as temperature of the laser focusing spot area was increased. These results indicated that electrical resistance of the laser focusing spot area was controlled by changing temperature on the laser focusing spot area.

DOI: 10.2961/jlmn.2014.03.0004
\end{abstract}

Keywords: Local heating, CW fiber laser, Titanium dioxide film, Electrical resistance

\section{Introduction}

Titanium dioxide $\left(\mathrm{TiO}_{2}\right)$ film is attractive material because it has unique properties such as photocatalytic properties [1] and biocompatibility [2]. A coating method by aerosol beam which is composed of submicron size functional ceramic particles has been developed to form functional ceramics film [3-5]. In this method, submicron-size ceramic particles are accelerated by a gas flow to velocities of several hundred $\mathrm{m} / \mathrm{s}$ and impact the substrate. As a result, a dense film is formed on the substrate. This coating method is performed at low temperature. The films can be formed at room temperature on plastic plates, glass plates and metal plates, respectively.

To expand the film application, formation of oxygen deficiencies in the film was one of the useful methods [6-9]. When the oxygen deficiencies were created in the film, band gap of $\mathrm{TiO}_{2}$ between conduction band and valence band is narrowed by creation of donor levels. Thus, electrical resistance of the film can be decreased. If oxygen deficiencies were created in the local area of the film, electrical resistance of the film was locally decreased. It was reported that oxygen deficiencies were created in the single crystal $\mathrm{TiO}_{2}$ by heating in the electrical furnace under vacuum [6] or reduction atmosphere $[7,8]$. In the $\mathrm{TiO}_{2}$ powder, oxygen deficiencies were also created by heating in the electrical furnace under reduction atmosphere [9]. These results show oxygen deficiencies could be formed in the $\mathrm{TiO}_{2}$ film by heating process. If oxygen deficiencies were created in the film by these heating processes in the electrical furnace, not only the film but also the substrate was heated. Then, the substrate might be damaged.

Local heating with continuous wave $(\mathrm{CW})$ fiber laser can be one of the useful methods for creation of oxygen deficiencies in the local area of the film without damage of substrate [10]. Then, mechanism of local heating process to the film with the fiber laser has not been elucidated yet. It was considered that local heating process to the film with the fiber laser was attributed to following two mechanisms. One is heating the substrate with the fiber laser as shown in Fig. 1 (a). Band gap of the $\mathrm{TiO}_{2}$ is about $3.2 \mathrm{eV}$. The fiber laser beam (wavelength is $1076 \mathrm{~nm}=1.16 \mathrm{eV}$ ) is not absorbed in the film. It is considered that substrate was initially heated because the fiber laser beam was absorbed in the substrate. The film was heated after thermal diffusion from substrate. The other is heating the film with the fiber laser as shown in Fig.1 (b). When the fiber laser is irradiated to the film, electric field of the fiber laser interacts with electron and atom of the $\mathrm{TiO}_{2}$. Then, position of the electron cloud is shifted relative to the nucleus. As a result, the polarization can be generated in the film during the fiber laser propagating. So, energy of the fiber laser can be directly absorbed in the film by the polarization. It is known that absorption of laser beam by polarization is derived from Dielectric Response Function by Lorentz Model $[11,12]$. 
a

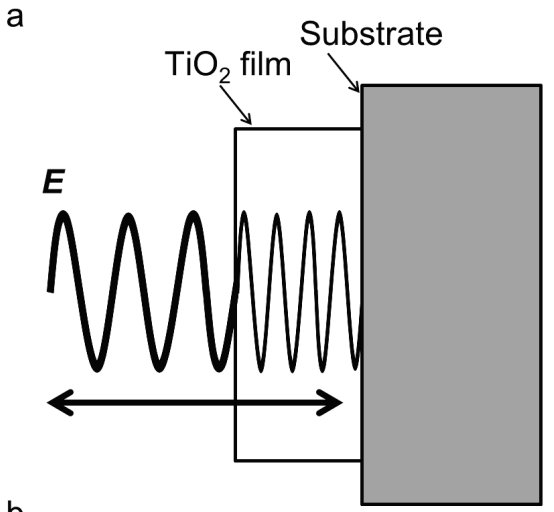

b

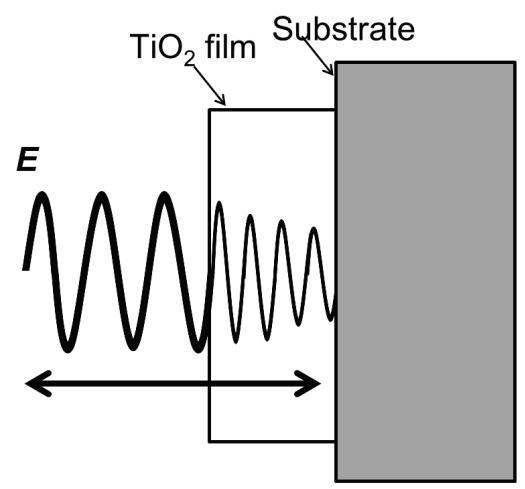

Fig. 1 (a) Schematic diagram of the fiber laser beam propagated in the film and (b) the fiber laser beam absorbed in the film. $E$ is the electric field of the fiber laser beam.

In our pre-experiments, the film could be melted by the fiber laser irradiation at higher laser intensity. This result indicated that temperature of the laser focusing spot area was increased over melting point of the film. Thus, temperature of the laser irradiated area might reach the temperature for oxygen deficiencies formation on the film by controlling the laser intensity of the fiber laser. Oxygen deficiencies were created in $\mathrm{TiO}_{2}$ single crystals of rutile at $800^{\circ} \mathrm{C}$ by heating in electric furnace under vacuum [6]. Therefore, oxygen deficiencies could be formed in the film by controlling the temperature of the film with the fiber laser in vacuum. Temperature measurement of the laser focusing spot area is very important for controlling the electrical resistance of the laser focusing spot area on the film. Temperature of the laser focusing spot area on the film by using the fiber laser in vacuum has not been measured yet.

In this study, the electrical resistance of the film was controlled by changing the temperature of the laser focusing spot area during local heating with the fiber laser in vacuum. Temperature of the laser focusing spot area was measured during changing the laser intensity. Electrical resistance of laser irradiated area was also measured. Relationship of temperature and electrical resistance of the laser focusing spot area was examined. Finally, mechanism of local heating of the film with the fiber laser was discussed. In the experiment, the film was formed on the stainless steel plate with an aerosol beam. The fiber laser focusing spot was scanned on the film surface in vacuum. The laser irradiated area was observed with optical microscope and scanning electron microscope (SEM). Temperature of the laser irradiated area during the fiber laser irradiation was measured by using the radiation thermometer. Electrical resistance of the laser irradiated area was measured by our two-terminal method.

\section{Experimental procedure}

The film coating system using an aerosol beam is shown in Fig. 2. The system primarily consisted of the aerosol chamber and a processing chamber connected by a tube. Anatase $\mathrm{TiO}_{2}$ particles with a size of about $200 \mathrm{~nm}$ were in an aerosol chamber. An aerosol beam was produced by mixing the particles and Helium $(\mathrm{He})$ gas using a vibration system. The processing chamber was pumped out using a mechanical booster and rotary pumps to create a pressure difference between the aerosol chamber and the processing chamber. The particles were accelerated by the flow of Helium gas and carried to the processing chamber through the tube and nozzle. The particles ejected from the nozzle impacted with the substrate and were deposited on the substrate surface. Stainless steel plate (Type 304) was used for substrate in this experiment.

Schematic diagrams of the fiber laser irradiation with temperature monitoring and scanning direction on the film were shown in Figs. 3 (a) and (b), respectively. A single mode $\mathrm{Yb}$ fiber laser was used in this experiment. In the fiber laser, $\mathrm{Yb}$ doped fiber was pumped with diode lasers (DL). The wavelength and maximum output power of the fiber laser was $1076 \mathrm{~nm}$ and $100 \mathrm{~W}$, respectively. The laser beam was focused on the film surface throughout the vacuum chamber by using a lens with $250 \mathrm{~mm}$ focal length. The Gaussian laser beam had a diameter of $500 \mu \mathrm{m}$ (at the $1 / \mathrm{e}^{2}$ intensity points) on the film. The laser focusing spot was scanned on the film surface by using the XY stage in vacuum $\left(8.0 \times 10^{-3} \mathrm{~Pa}\right)$ as shown in Fig. $3(\mathrm{~b})$. Scanning speed and distance were $1 \mathrm{~mm} / \mathrm{s}$ and $2.5 \mathrm{~mm}$, respectively. The power of the fiber laser on the film was changed from 2.4 $\mathrm{W}$ to $15.9 \mathrm{~W}$ by controlling the DL current. Then, laser intensity was calculated from $4.8 \times 10^{2}$ to $3.0 \times 10^{3} \mathrm{~W} / \mathrm{cm}^{2}$. Temperature measurement of the laser focusing spot area was conducted with a radiation thermometer as shown in Fig. 3 (a). Our radiation thermometer was activated in the range of 300 to $2000^{\circ} \mathrm{C}$. Spectra region for activating the radiation thermometer was in the range of 1.95 to $2.5 \mu \mathrm{m}$.

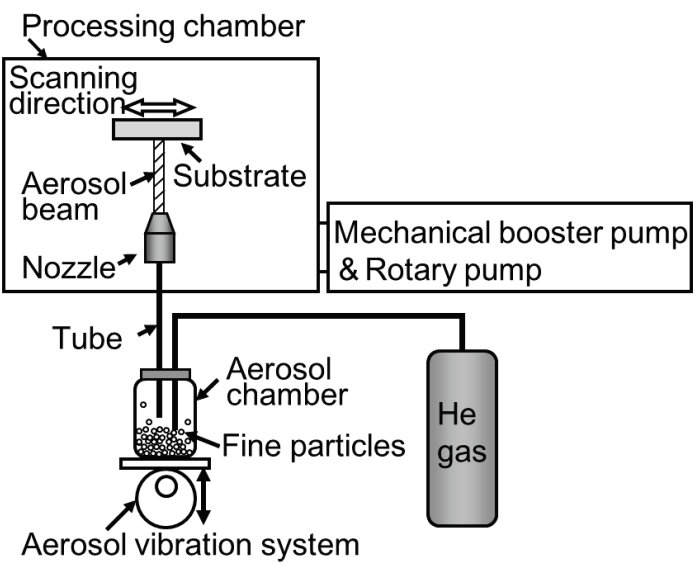

Fig. 2 Schematic diagram of the film coating system with an aerosol beam. 
a

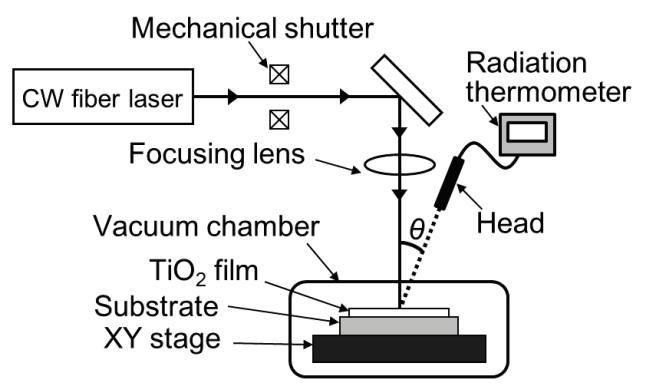

b

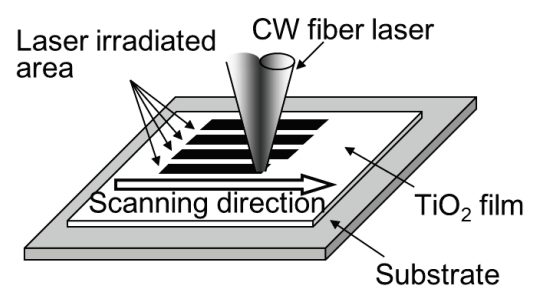

Fig. 3 (a) Schematic diagram of experimental setup for the fiber laser irradiation with temperature measurement. (b) Scanning direction of the laser focusing spot on the film.

Angle of the infrared light of radiation thermometer from the film during the fiber laser irradiation, $\theta$ in Fig. 3 (a), was fixed about $20^{\circ}$. Emissivity of the film was selected about 0.5 [13]. Measurement area of radiation thermometer was about $300 \mu \mathrm{m}$. Size of laser focusing spot was larger than measurement area. Thus, temperature of laser irradiated area can be detected by our radiation thermometer.

After the fiber laser irradiation, the film surface was observed with optical microscope and SEM. The electrical resistances of laser irradiated area were measured by twoterminal method using two probes, a constant-voltage source, and an ammeter. Two steel probes with a tip diameter of about $30 \mu \mathrm{m}$ were used. The two probes were both located along a laser-scanned line. The distance between the probes was $1 \mathrm{~mm}$ and a voltage of $10 \mathrm{~V}$ was applied between the two tips. The electrical resistances were determined by measuring the electrical current between the two probes. The bare films without laser irradiation had an electrical resistance too large to measure by our twoterminal method. Transmittance of the film was measured by using a spectrometer.

\section{Results and Discussion}

Optical and SEM image of the film on the stainless steel plate after aerosol beam irradiation are shown in Figs. 4 (a) and (b), respectively. As shown in Fig. 4 (a), the film was formed in $10 \mathrm{~mm} \times 10 \mathrm{~mm}$ on the stainless steel plate. Submicron size $\mathrm{TiO}_{2}$ particles were used for the film formation with an aerosol beam. $\mathrm{TiO}_{2}$ particles were collided and crushed during aerosol beam irradiation. Figure 4 (b) shows submicron size $\mathrm{TiO}_{2}$ particles were not observed after aerosol beam irradiation. These results suggested that the film was formed on substrate after aerosol beam irradiation. Cross section of the film was observed by SEM as shown in Figs. 5 (a) and (b), respectively. As Figs. 5 (a) and (b) show, the dense film was produced on the substrate by

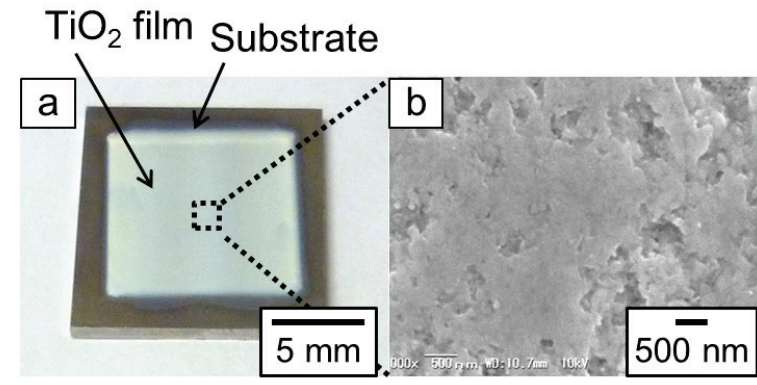

Fig. 4 (a) Optical image of the film on stainless steel plate after aerosol beam irradiation. (b) SEM image of film surface.

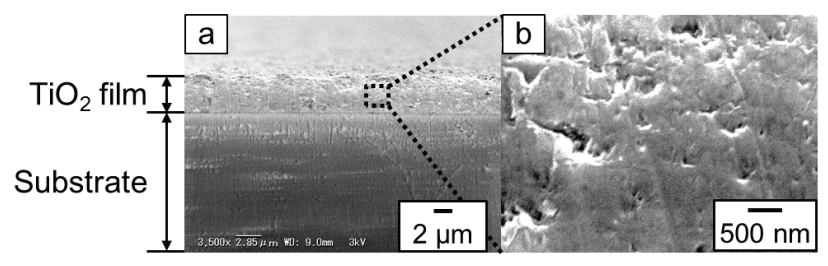

Fig. 5 (a) Optical image of the film on stainless steel plate after aerosol beam irradiation. (b) SEM image of film surface.

aerosol beam irradiation. The film thickness was about 4 $\mu \mathrm{m}$.

Transmittance spectra of the film in the wavelength region from 300 to $1300 \mathrm{~nm}$ are shown in Fig. 6. Silica glass was used as the substrate. As shown in Fig. 6, the transmittance at wavelength of $1076 \mathrm{~nm}$ was about $80 \%$. The fiber laser beam with the wavelength of $1076 \mathrm{~nm}$ can be absorbed in the film surface.

Optical image of the laser focusing spot scanned area on the film with the fiber laser in vacuum at the laser intensities of $4.8 \times 10^{2}, 8.7 \times 10^{2}, 1.1 \times 10^{3}, 1.4 \times 10^{3}, 1.8 \times 10^{3}$, $2.1 \times 10^{3}, 2.4 \times 10^{3}, 2.7 \times 10^{3}$ and $3.0 \times 10^{3} \mathrm{~W} / \mathrm{cm}^{2}$ are shown at (a), (b), (c), (d), (e), (f), (g), (h) and (i) in Fig. 7 respectively. As Fig. 7 shows, laser irradiated area was darkened at the laser intensity over $1.1 \times 10^{3} \mathrm{~W} / \mathrm{cm}^{2}$. At 8.7 $\times 10^{2} \mathrm{~W} / \mathrm{cm}^{2}$, right side of laser irradiated area was darkened as shown in Fig. 7 (b). It is known that darkened $\mathrm{TiO}_{2}$ might be caused by creation of oxygen deficiencies [7,8,14]. Thus, oxygen deficiencies might be created in the local area of the film by the fiber laser in vacuum over $1.1 \times 10^{3}$ $\mathrm{W} / \mathrm{cm}^{2}$.

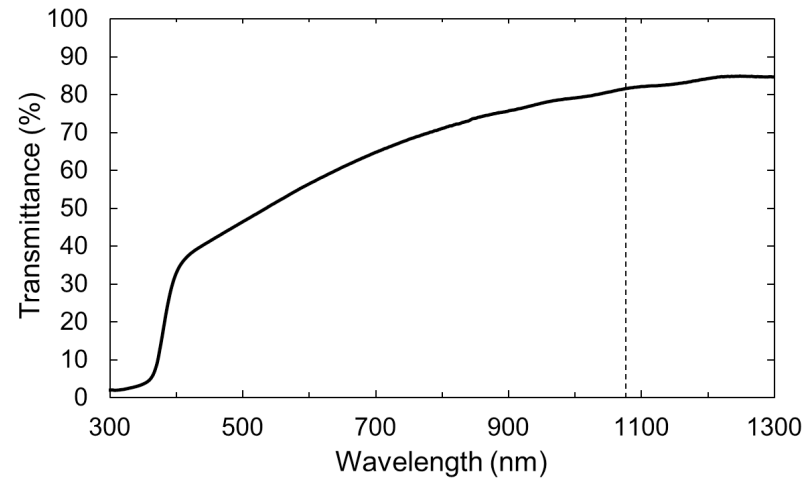

Fig. 6 Transmittance spectra of $\mathrm{TiO}_{2}$ film coated with aerosol beam. 


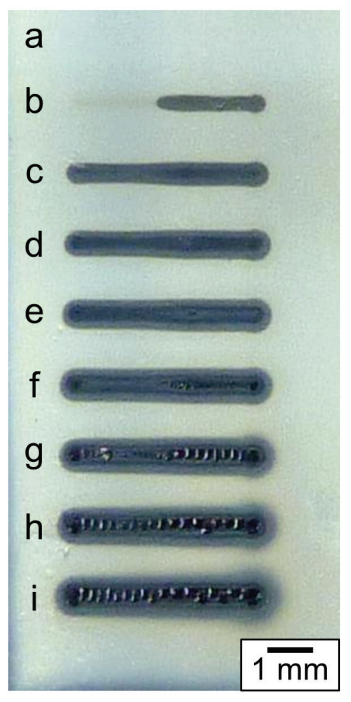

Fig. 7 Optical image of the film after the fiber laser irradiation in the vacuum: laser intensities were changed at (a) $4.8 \times 10^{2}$, (b) $8.7 \times 10^{2}$, (c) $1.1 \times$ $10^{3}$, (d) $1.4 \times 10^{3}$, (e) $1.8 \times 10^{3}$, (f) $2.1 \times 10^{3}$, (g) $2.4 \times 10^{3}$, (h) $2.7 \times 10^{3}$ and (i) $3.0 \times 10^{3}$ $\mathrm{W} / \mathrm{cm}^{2}$, respectively.

SEM image of bare film surface is shown in Fig. 8 (a). SEM images of laser irradiated area at the laser intensities from $4.8 \times 10^{2} \mathrm{~W} / \mathrm{cm}^{2}$ to $3.0 \times 10^{3} \mathrm{~J} / \mathrm{cm}^{2}$ are shown in Figs. 8 (b), (c), (d), (e), (f), (g), (h), (i) and (j), respectively. As Figs. 8 (d), (e), (f) and (g) show, the topography of the darkened area was almost not changed by the fiber laser irradiation at the laser intensities from $1.1 \times 10^{3} \mathrm{~W} / \mathrm{cm}^{2}$ to $2.1 \times 10^{3} \mathrm{~W} / \mathrm{cm}^{2}$. However, the topography of darkened area was drastically changed over $2.4 \times 10^{3} \mathrm{~W} / \mathrm{cm}^{2}$ as shown in Figs. 8 (h), (i) and (j). Then, size of grain boundary was increased as shown in Figs.8 (h), (i) and (j). These results suggested that the film and the substrate were not melted at the laser intensities from $1.1 \times 10^{3} \mathrm{~W} / \mathrm{cm}^{2}$ to 2.1 $\times 10^{3} \mathrm{~W} / \mathrm{cm}^{2}$.

Squares in Fig. 9 show temperature of the laser focusing spot area during the fiber laser irradiation in vacuum at various laser intensities. As shown in Fig. 9, temperature of the laser focusing spot area was increased from about $600^{\circ} \mathrm{C}$ to about $1900^{\circ} \mathrm{C}$ as the laser intensity was increased from $4.8 \times 10^{2} \mathrm{~W} / \mathrm{cm}^{2}$ to $3.0 \times 10^{3} \mathrm{~W} / \mathrm{cm}^{2}$. These temperatures were average value from temperature measurement. When the laser irradiated area was darkened at the laser intensities from $1.1 \times 10^{3} \mathrm{~W} / \mathrm{cm}^{2}$ to $2.1 \times 10^{3} \mathrm{~W} / \mathrm{cm}^{2}$ as shown in Fig. 7, temperature of the laser focusing spot area varied from $1000^{\circ} \mathrm{C}$ to $1400^{\circ} \mathrm{C}$ as shown in Fig. 9. Melting point of $\mathrm{TiO}_{2}$ and stainless steel plate was about $1800^{\circ} \mathrm{C}$ and $1500^{\circ} \mathrm{C}$, respectively. Temperature of the laser focusing spot area at the laser intensities from $1.1 \times 10^{3} \mathrm{~W} / \mathrm{cm}^{2}$ to $2.1 \times 10^{3} \mathrm{~W} / \mathrm{cm}^{2}$ was lower than melting point of the film and stainless steel plate. These results indicated that the darkened areas of the film and the substrate were not melted at the laser intensities from $1.1 \times 10^{3} \mathrm{~W} / \mathrm{cm}^{2}$ to $2.1 \times 10^{3}$ $\mathrm{W} / \mathrm{cm}^{2}$. Temperature of right side of laser irradiated area at laser intensity of $8.7 \times 10^{2} \mathrm{~W} / \mathrm{cm}^{2}$ reached over $800^{\circ} \mathrm{C}$. As describe before, oxygen deficiencies were formed in $\mathrm{TiO}_{2}$ single crystals when temperature reached over $800^{\circ} \mathrm{C}$ [6].

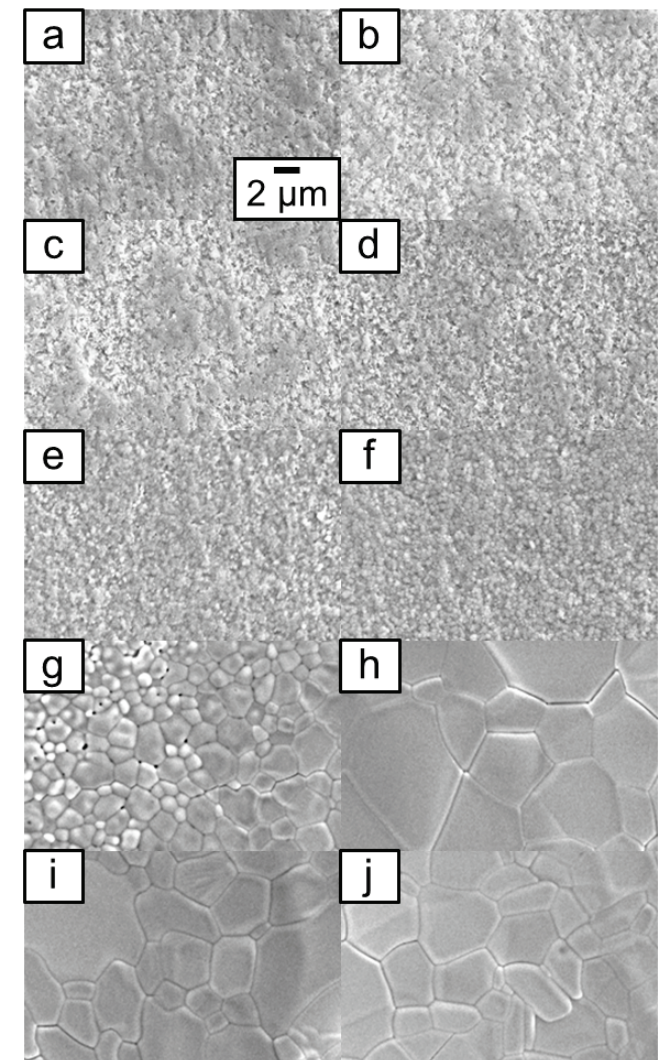

Fig. 8 SEM images of the film surface: (a) bare the film (no laser irradiation), the fiber laser irradiation area in the vacuum at (b) $4.8 \times 10^{2}$, (c) $8.7 \times 10^{2}$, (d) $1.1 \times 10^{3}$, (e) $1.4 \times 10^{3}$, (f) $1.8 \times 10^{3}$, (g) 2.1 $\times 10^{3}$, (h) $2.4 \times 10^{3}$, (i) $2.7 \times 10^{3}$ and (j) $3.0 \times$ $10^{3} \mathrm{~W} / \mathrm{cm}^{2}$, respectively.

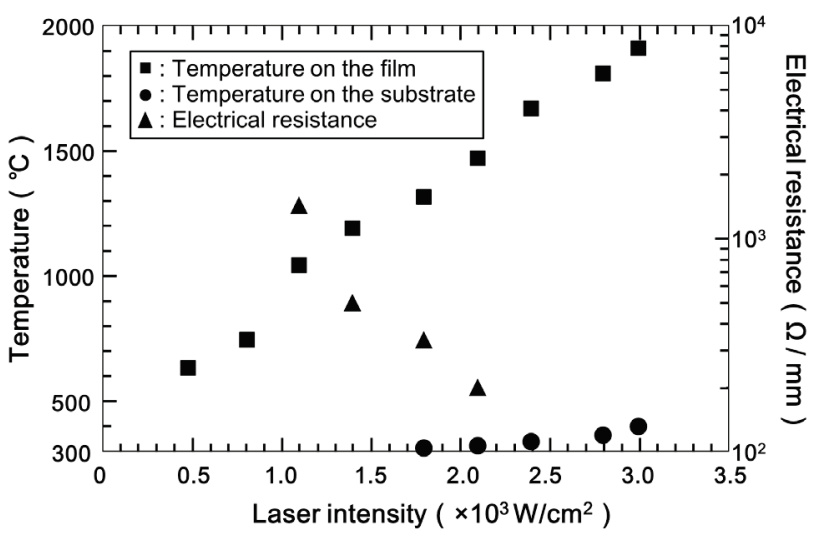

Fig. 9 Electrical resistances and temperature of the fiber laser focusing spot area on the film and substrate under vacuum as a function of laser intensities.

Thus, right side of laser irradiated area was darkened at 8.7 $\times 10^{2} \mathrm{~W} / \mathrm{cm}^{2}$.

Triangles in Fig. 9 show the electrical resistances of the laser irradiated areas on the film after the fiber laser irradiation in vacuum at various laser intensities. Electrical resistance of laser irradiated area under $8.7 \times 10^{2} \mathrm{~W} / \mathrm{cm}^{2}$ was not detected because electrical resistance was too high by our two-terminal method as shown in Fig. 9. The electrical resistances of the fiber laser irradiated area were decreased from $1.4 \times 10^{3} \Omega / \mathrm{mm}$ to $2.0 \times 10^{2} \Omega / \mathrm{mm}$ as the laser inten- 
sity was increased from $1.1 \times 10^{3} \mathrm{~W} / \mathrm{cm}^{2}$ to $2.1 \times 10^{3}$ $\mathrm{W} / \mathrm{cm}^{2}$. Thus, electrical resistance of the laser focusing spot area was decreased from $1.4 \times 10^{3} \Omega / \mathrm{mm}$ to $2.0 \times 10^{2}$ $\Omega / \mathrm{mm}$ as temperature of the laser focusing spot area was increased from $1000^{\circ} \mathrm{C}$ to $1400^{\circ} \mathrm{C}$. Over $2.4 \times 10^{3} \mathrm{~W} / \mathrm{cm}^{2}$, electrical resistance was not detected by our two-terminal method because the film and substrate was melted. In this experiments, electrical resistance of the laser focusing spot area was controlled by changing temperature on the laser focusing spot area from $1000^{\circ} \mathrm{C}$ to $1400^{\circ} \mathrm{C}$.

Temperature of the laser focusing spot area on the substrate after the fiber laser irradiation in vacuum at various laser intensities was also shown in with circles in Fig. 9. As shown in Fig. 9, the temperature on the substrate was not changed at the laser intensities under $1.4 \times 10^{3} \mathrm{~W} / \mathrm{cm}^{2}$. Over $1.8 \times 10^{3} \mathrm{~W} / \mathrm{cm}^{2}$, temperature on the substrate was increased from $300^{\circ} \mathrm{C}$ to $400^{\circ} \mathrm{C}$. Oxygen deficiencies were not created in the $\mathrm{TiO}_{2}$ under $800^{\circ} \mathrm{C}$ [6]. Temperature of the substrate did not reach the temperature for oxygen deficiencies formation. These results suggested that oxygen deficiencies were not formed in the film after thermal diffusion from substrate and the fiber laser beam was initially absorbed in only the film during the fiber laser irradiation. Hence, mechanism of local heating to the film with the fiber laser can be attributed to absorption of the fiber laser beam in the film during the fiber laser irradiation as show in Fig. 1 (b). In the future, we intend to report more details of the mechanism for absorption of the fiber laser beam in the film.

\section{Summary}

The electrical resistance of the film was controlled by the temperature monitoring of the laser irradiate area during local heating with the fiber laser. Temperature of the laser focusing spot was increased as the laser intensity was increased. Electrical resistance of the laser focusing spot area was decreased as the laser intensity was increased. Thus, electrical resistance of the laser focusing spot area was decreased as temperature of the laser focusing spot area was increased. These results indicated that electrical resistance of the laser focusing spot area was controlled by changing temperature on the laser focusing spot area.

\section{Acknowledgments}

I would like to express my gratitude to Dr. H. Furukawa for helpful discussion and advice.

\section{References}

[1] T. A. Fujishima, K. Honda, Electrochemical photolysis of water at a semiconductor electrode, Nature. 238 (1972) 37-38.
[2] X. Liu, P. K. Chub, C. Ding, Surface modification of titanium, titanium alloys and related materials for biomedical applications, Mater. Sci. Eng. R 47 (2004) 49121.

[3] J. Akedo, M. Ichiki, K. Kikuchi, K. Maeda, Jet molding system for realization of three-dimensional microstructures, Sens. Actuators A. 69 (1998) 106-112.

[4] M. Tsukamoto, T. Fujihara, N. Abe, S. Miyake, M. Katto, T. Nakayama, J. Akedo, Hydroxyapatite coating on titanium plate with an ultrafine particle beam, Jpn. J. Appl. Phys. 42 (2003) L120-L122.

[5] M. Tsukamoto, N. Nakamura, A. Kitajima, J. Morimoto, Nobuyuki Abe and J. Akedo, "Hydroxyapatite film formation on polylactic acid plate by aerosol beam irradiation", Jpn. J. Appl. Phys. 45. 10A (2006) 78407844.

[6] E. Iguchi, K. Yajima, Diffusion of oxygen vacancies in reduced rutile $\left(\mathrm{TiO}_{2}\right)$, J. Phys. Soc. Jpn. 32. 5 (1972) 1415-1421.

[7] D.C. Clonemeyer, Infrared absorption of reduced rutile $\mathrm{TiO}_{2}$ single crystals, Phys. Rev. 113. 5 (1959) 12221226.

[8] T. Sekiya, T. Yagisawa, N. Kamiya, D.D. Mulmi, S. Kurita, Y. Murakami, T. Kodaira, Defects in anatase $\mathrm{TiO}_{2}$ single crystal controlled by heat treatments, J. Phys. Soc. Jpn. 73.3 (2004) 703-710.

[9] H. Liu, H.T. Ma, X.Z. Li, W.Z. Li, M. Wu, X.H. Bao, The enhancement of $\mathrm{TiO}_{2}$ photocatalytic activity by hydrogen thermal treatment, Chemosphere. 50 (2003) 39-46.

[10] T. Shinonaga, M. Tsukamoto, M. Takahashi, M. Fujita, N. Abe, Formation of $\mathrm{TiO}_{2}$ film with lower electrical resistance by aerosol beam and fiber laser irradiation, Appl. Phys. A. Mater. Sci. Proc. (2012) 112 (2013) 5760.

[11]H. Furukawa, K. Fujita, S. Moriya, Simulation code development of laser ablation on ignition of rocket engine by laser, J. Plasma Fusion Res. 87.9 (2011) 642649 , in japanese.

[12]T. Saiki, Y. Toda, Sentan gijyutu siri-zu 2. Hikari bussei nyuumon - busshitsu no seishitsu wo shirou-, Asakura Shoten, Tokyo, 2012, pp. 27-31, in Japanese.

[13] T. Manabe, Sekigaisen gijyutu, proceeding of the infrared society of Japan, 9 (1984) 68-82, in Japanese.

[14] I. Nakamura, N. Negishi, S. Kutsuna, T. Ihara, S. Sugihara, K. Takeuchi, Role of oxygen vacancy in the plasma-treated $\mathrm{TiO}_{2}$ photocatalyst with visible light activity for NO removal, J. of Mol. Catal. A. 161 (2000) 205-212.

(Received: January 10, 2014, Accepted: July 22, 2014) 